\title{
Influence of Electrolyte Refreshing on the Photoelectrochemical Performance of Fiber-Shaped Dye-Sensitized Solar Cells
}

\author{
Zhibin Lv, Hongwei Wu, Xin Cai, Yongping Fu, Dan Wang, Zengze Chu, and Dechun Zou
}

Beijing National Laboratory for Molecular Sciences, Key Laboratory of Polymer Chemistry and Physics of Ministry of Education, College of Chemistry and Molecular Engineering, Peking University, Beijing 100871, China

Correspondence should be addressed to Dechun Zou, dczou@pku.edu.cn

Received 2 October 2011; Accepted 30 November 2011

Academic Editor: Gerrit Boschloo

Copyright ( $) 2012$ Zhibin Lv et al. This is an open access article distributed under the Creative Commons Attribution License, which permits unrestricted use, distribution, and reproduction in any medium, provided the original work is properly cited.

Given the convenient sealing of fiber-shaped dye-sensitized solar cells (FDSSCs), the electrolyte refreshing effect on the photoelectrochemical performance of FDSSCs was studied. The electron transport and interfacial recombination kinetics were also systematically investigated by electrochemical impedance spectroscopy. With increased electrolyte refreshing times from 0 to 10 , the open-circuit voltage $\left(V_{\mathrm{oc}}\right)$ and fill factor $(\mathrm{FF})$ increased, whereas the photocurrent density $\left(J_{\mathrm{sc}}\right)$ and power conversion efficiency (PCE) significantly decreased. The increased $V_{\mathrm{oc}}$ was mainly ascribed to the electron recombination resistance $\left(R_{\mathrm{ct}, \mathrm{wE}}\right)$ at the $\mathrm{TiO}_{2}$ /electrolyte interface and electron lifetime. The decreased $J_{\mathrm{sc}}$ and PCE were due to dye desorption and the increase of series resistance. Further investigation proved that $\mathrm{Li}^{+}$played a vital role in increasing $V_{\mathrm{oc}}$ as electrolyte refreshing and $\mathrm{Li}^{+}$had $\mathrm{more}$ significant impact than TBP (tert-butyl pyridine) on maintaining high $V_{\text {oc }}$.

\section{Introduction}

Given their high-energy conversion efficiency and simple fabrication process, dye-sensitized solar cells (DSSCs) have been attracting worldwide scientific and technological interest for decades [1-3]. Research on the optimization of materials and fabrication procedures is progressive.

Consequently, current planar DSSCs using $\mathrm{I}_{3}^{-} / \mathrm{I}^{-}$electrolytes, have achieved up to $11 \%-12 \%$ conversion efficiency [46 ], and the efficiency of large-scale modules has also reached $8 \%$ with aperture areas of more than $20 \mathrm{~cm}^{2}$ [7]. DSSCs are considered as promising alternatives to conventional siliconbased photovoltaic devices for sustainable, low-cost, and environment-friendly energy supply. However, there are still obstacles to overcome, such as cost, limited efficiency in the large-scale module, electrolyte leakage, cell sealing, and stability.

Fiber solar cells have received great attention in recent years [8-22]. Their advantages over DSSCs having traditional sandwiched planar structure include the following. (1) Nonflat structured solar cells get rid of the dependence on transparent conductive oxides (TCOs) [8]. Traditional solar cells and the reported tubular solar cells still use TCOs, which usually account for $30 \%-50 \%$ of total cell costs [23]. (2) The fiber cell is a macro-one-dimensional structure, and has a smaller package area ratio than the two-dimensional structure. Making a larger cell only requires increasing the length of the cell. When the cell is increased to a certain size, the package area of the cell remains basically unchanged [20]. (3) The flexible fiber cell can directly adopt the traditional preparation technology. In contrast, special technologies must be adopted to create all kinds of traditional flexible flat cells (like OPVs and planar DSSCs) to ensure that the flexible substrate will not be damaged during the preparation process, such as low temperatures. (4) Existing textile techniques can be directly used in weaving for the mass production of fiber cells. This method is another further improvement of the traditional roll-to-roll technology for producing flexible electronic devices [18, 24].

The advancements in fiber solar cells, including fibershaped organic solar cells and fiber-shaped DSSCs (FDSSCs), have thus far been impressive $[8,9,11]$. The highest power 


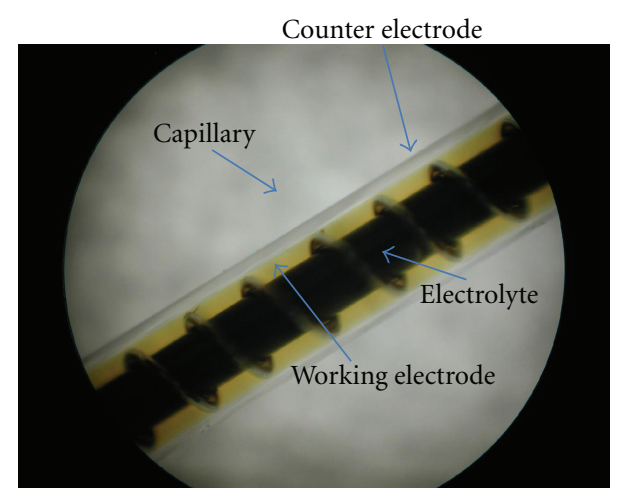

Figure 1: An optical photo of FDSSC structure details.

efficiency of FDSSCs ever reported is above 7\% [18]. FDSSCs not only address the problems of traditional flat cells, but also provide some new features to elucidate the factors that affect their performances. For example, Fu et al. [18] have studied the three-dimensional light collecting ability of FDSSCs. FDSSCs are found to be able to harvest surrounding light efficiently to double their power output. Under high light intensity, FDSSCs combined with a condenser also still has a relatively high output power and fill factor, with little performance decline. O'Connor et al. [14] have proposed a new type of solar cell that combines a series of fiber cell units with narrow-band spectrum absorption. A proper arrangement in space is adopted to realize full-spectrum absorption of the sun spectra, resulting in $17 \%$ theoretical power convention efficiency. All these above results are difficult to achieve when using planar DSSCs.

FDSSCs act as units, and they are easily encapsulated because only one end or both ends of the capillary need to be sealed during the sealing process [20]. This fact enables the possibility of more conveniently renewing the electrolyte, in contrast to planar DSSCs whose electrolytes cannot be refreshed once they are sealed tightly. In the present paper, the effect of electrolyte refreshing on the photovoltaic performance of FDSSCs was studied. The electron transport and interfacial recombination kinetics were also systematically investigated using electron impedance spectroscopy (EIS).

\section{Experimental}

2.1. Materials. All chemicals and solvents used were of pure quality. The Ti filament ( $99.7 \%$ pure, diameter $=0.25 \mathrm{~mm}$ ) was purchased from Alfa Aesar. LiI, $\mathrm{I}_{2}$, and 4-tetrabutylpyridine (TBP) were purchased from Aldrich. Acetonitrile $\left(\mathrm{CH}_{3} \mathrm{CN}\right.$, GR: guaranteed reagent) was purchased from Siyou Inc., Tianjin, China. N719 dye $\left(\left[\left(\mathrm{C}_{4} \mathrm{H}_{9}\right)_{4} \mathrm{~N}\right]_{2}\left[\mathrm{Ru}(\mathrm{II}) \mathrm{L}_{2}\right.\right.$ $\left.(\mathrm{NCS})_{2}\right]$, where $\mathrm{L}=2,2$-bipyridyl-4,4 dicarboxylic acid; ruthenium TBA535) and 1-butyl-3-methylimidazolium iodide (BMII) were from the Dalian Rainbow Light Solar Technology Development Co., Ltd. The $\mathrm{TiO}_{2}$ colloid was prepared as follows. About $12.0 \mathrm{~mL}$ of tetra-butyl titanate (Aldrich) and $2.0 \mathrm{~mL}$ of acetic acid were mixed with vigorous stirring. The mixture was slowly dropped into $60.0 \mathrm{~mL}$ of water, and
$0.5 \mathrm{~mL}$ of $65 \%$ nitric acid was added to the system. After stirring for $2 \mathrm{~h}$ in an oil bath at $80^{\circ} \mathrm{C}, 35 \mathrm{~mL}$ of the mixture was transferred into the autoclave and left undisturbed at $220^{\circ} \mathrm{C}$ for $12 \mathrm{~h}$. After removing part of the solvent, $0.6 \mathrm{~g}$ of polyethylene oxide $\left(M_{w}=4000\right.$; Aldrich $)$ was added and the $\mathrm{TiO}_{2}$ colloid was ready.

2.2. Fabrication of FDSSCs. The Ti wires were cleaned using acetone, isopropanol, and then ethanol. The $\mathrm{Ti}$ wires were immersed into the prepared $\mathrm{TiO}_{2}$ colloid and dipped in and out several times. Sintering at $400^{\circ} \mathrm{C}$ for 5 min followed. A thin layer of $\mathrm{TiO}_{2}$ film was formed on the Ti wire. The above step was repeated until the required thickness of the $\mathrm{TiO}_{2}$ film was obtained. The $\mathrm{TiO}_{2}$-coated electrode was sintered at $450^{\circ} \mathrm{C}$ for $30 \mathrm{~min}$. The electrode was sensitized in a $10^{-4} \mathrm{M}$ N719 ethanol solution for $24 \mathrm{~h}$ to obtain the sensitized working electrode. The counterelectrode was a Pt wire $40 \mu \mathrm{m}$ in diameter. The Pt wire was uniformly and spirally wound onto the photoanode and then inserted into the sealing capillary $(0.5 \mathrm{~mm}$ inner diameter and $0.85 \mathrm{~mm}$ outer diameter $)$ filled with the electrolyte. This electrolyte contained $0.04 \mathrm{M}$ iodine, 0.6 M BMII, 0.05 M LiI, and 0.30 M TBP in acetonitrile. The capillary was sealed with wax to prevent the electrolyte leakage. Each time refreshing the electrolyte, the wax was melted to decapsulate the FDSSC. The used electrolyte was removed, and the unsealed FDSSCs were allowed to suck the fresh electrolyte by capillarity. Finally, the cells were sealed again using wax.

2.3. Measurement and Methods. All device tests and short circuit current responses were conducted on a Keithley Model 2000, with sunlight simulator (YS-55, Japan). The illumination intensity is $100 \mathrm{~mW} / \mathrm{cm}^{2}$. The aperture area of the cell was obtained from the project area $A_{\text {pron, }}$ which was equal to twice the sum of the $\mathrm{Ti}$ wire diameter and $\mathrm{TiO}_{2}$ film thickness, multiplied by the length of the device. The short circuit current density $J_{\text {sc }}$ was $I / A_{\text {proj }}$ ( $I$ is the short circuit current). The power conversion efficiency PCE was $J_{\mathrm{sc}} \times V_{\mathrm{oc}} \times \mathrm{FF} / P_{\text {in }}$, where $V_{\mathrm{oc}}$ is the open-circuit voltage, FF is the fill factor, and $P_{\text {in }}$ is the intensity of incident light. The electrochemical impedance spectrum was obtained using PGSTAT302N (Autolab Corp., Switzerland) within the frequency range of $0.05 \mathrm{~Hz}$ to $300 \mathrm{kHz}$ at room temperature and was fitted using Nova 1.7 software.

\section{Results and Discussion}

Generally, the electrolytes of FTO-glass-based planar DSSCs could not be or difficultly refreshed once there is already an electrolyte leakage. FDSSCs overcome this problem because of their simple and detachable sealing methods [20]. The new issue is whether the electrolyte refreshing times affect the performance of FDSSCs. Figure 1 is an optical photo of FDSSC, in which the details of FDSSC are demonstrated. The FDSSC consists a counterelectrode wrapped around the working electrode, which then encapsulated in a capillary filled with electrolytes. Figure 2 shows the photocurrent density-voltage $(J-V)$ characteristics of devices with electrolyte refreshing 


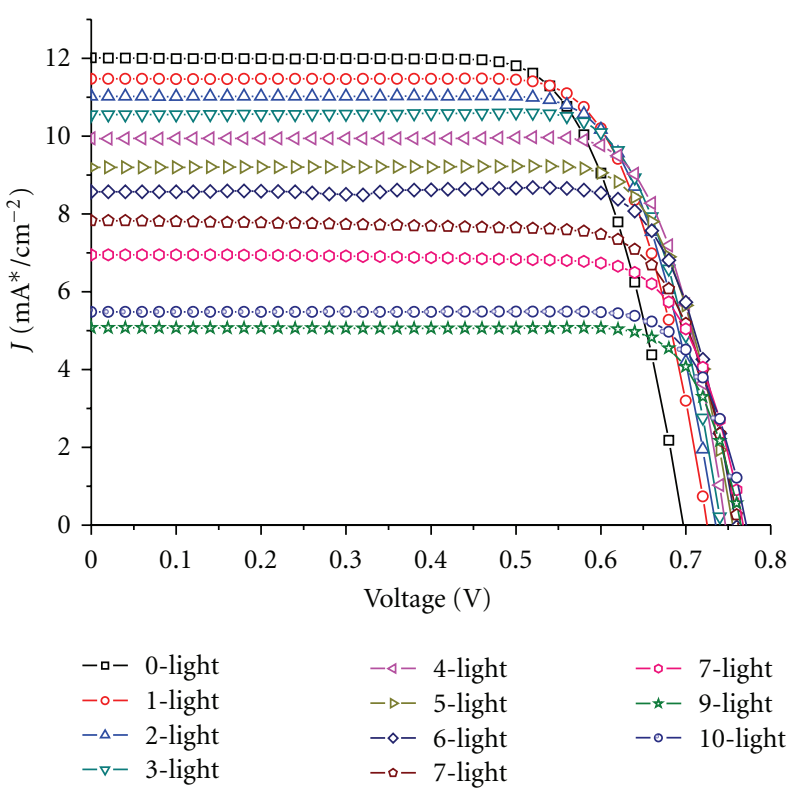

(a)

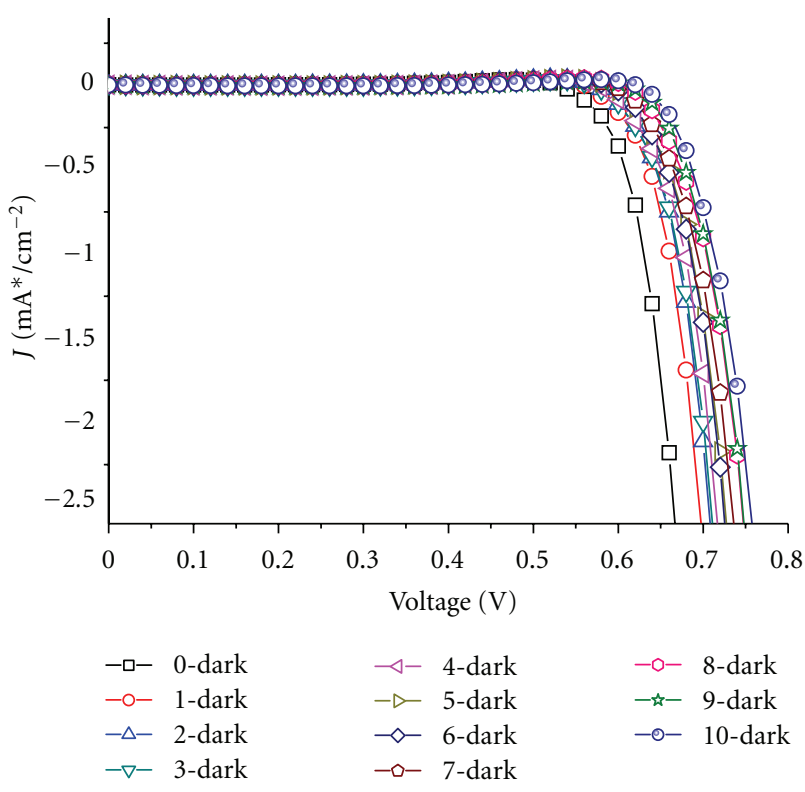

(b)

FIgURE 2: (a) Photocurrent density-voltage $(J-V)$ characteristics of devices with electrolyte refreshing times under AM 1.5 illumination $(100 \mathrm{~mW} / \mathrm{cm})$. (b) $J-V$ curves of the device with electrolyte refreshing times under dark condition.

times under air mass (AM) 1.5 illumination $\left(100 \mathrm{~mW} / \mathrm{cm}^{2}\right)$ (Figure 2(a)) and under dark conditions (Figure 2(b)). The dependency of the photovoltaic performance parameters $\left(J_{s c}\right.$, $V_{\mathrm{oc}}, \mathrm{FF}$, and PCE) on the electrolyte refreshing times is shown in Figure 3. With increased electrolyte refreshing times from 0 to $10, V_{\text {oc }}$ gradually increased from 0.697 to $0.760 \mathrm{~V}$. FF also increased from 0.730 to 0.820 , whereas $J_{\text {sc }}$ decreased from 12.01 to $5.07 \mathrm{~mA} / \mathrm{cm}^{2}$. The PCE was at the apex when the electrolyte was refreshed for the first time. At this point, $V_{\mathrm{oc}}$, $J_{s c}, F F$, and PCE of the FDSSCs were $0.725 \mathrm{~V}, 11.47 \mathrm{~mA} / \mathrm{cm}^{2}$, 0.749 , and $6.23 \%$, respectively. During the second electrolyte refreshing, the PCE began to drop. All these results indicated that certain phenomena occurred inside the FDSSCs when the electrolytes were frequently refreshed.

In a renewable electrochemical system $[25,26]$

$$
V_{\mathrm{oc}}=\left(\frac{k T}{e}\right) \ln \left(\frac{I_{\mathrm{inj}}}{n_{\mathrm{cb}} k_{\mathrm{et}}\left[\mathrm{I}_{3}^{-}\right]}\right),
$$

where $I_{\text {inj }}$ is the photocurrent injected to the $\mathrm{TiO}_{2}$ from the excited dye, $n_{\mathrm{cb}}$ is the photoelectron density of the conductive band, and $k_{\text {et }}$ is the constant of the reaction, and

$$
\mathrm{I}_{3}^{-}+2 e_{\mathrm{cb}}\left(\mathrm{TiO}_{2}\right) \longrightarrow 3 \mathrm{I}^{-},
$$

where $I_{3}^{-}$can enter into tiny cavities inaccessible to dye molecules. The second equation is related to the dark reaction. As shown in Figure 1(b), the dark current density decreased with increased electrolyte refreshing times, especially during the initial stage. This finding meant that, with electrolyte refreshing, the dark reaction was restrained and $k_{\text {et }}$ decreased. Consequently, there was less electron recombination between the electrons at the $\mathrm{TiO}_{2}$ conduction band and $\mathrm{I}_{3}^{-}$in the electrolyte. According to (1), $V_{\text {oc }}$ increases for the same solar cell if weakened by the dark reaction.
As presented in Figure 3, $J_{\mathrm{sc}}$ and PCE also both decreased with increased electrolyte refreshing times. EIS was used to investigate these tendencies. EIS measured in the dark is a well-known technique for studying charge-transfer processes [27-30]. Wide ranges of electrochemical processes and internal resistances that govern the performance of DSSCs could be analyzed by this method. Important general conclusions have been made based on EIS studies. The impedance spectra of DSSCs consist of three components [29,30], namely, charge transfers at the Pt/electrolyte and $\mathrm{TiO}_{2} /$ electrolyte interfaces, as well as the diffusion of $\mathrm{I}_{3}^{-}$in the electrolyte. Each time the electrolyte is refreshed, the impedance data of the FDSSs were acquired at a forward bias of $0.75 \mathrm{~V}$ in the dark. Figure 4 shows the Nyquist plots of the corresponding FDSSCs with various electrolyte refreshing times in the dark at an applied forward bias of $0.75 \mathrm{~V}$. The inset in Figure 3 is the equivalent circuit used to fit the experimental data $[30,31]$. From left to right in Figure 3, the first arc is the interface between the counterelectrode and electrolyte; the second arc is the interface between $\mathrm{TiO}_{2}$ and the electrolyte. In the equivalent circuit, $R_{\mathrm{s}}$ is the ohmic serial resistance. $R_{\mathrm{S}}$ represented the transmission resistance of the conducting substrate as well as the interface resistance between the conducting substrate and $\mathrm{TiO}_{2} . R_{\mathrm{ct}, \mathrm{CE}}$ : is the charge transfer resistance, by which the regeneration of $\mathrm{I}^{-}$at the counterelectrode is characterized. Parallel to $R_{\mathrm{ct}, \mathrm{CE}}$, the constant phased element (CPE) describes the double-layer capacitance $C_{\mathrm{Pt}}$ at the counterelectrode/electrolyte interface.

$$
\begin{aligned}
\mathrm{CPE} & =Y_{0}(j \omega)^{-n}, \quad 0<n \leq 1, n=1, \\
\mathrm{CPE} & =\frac{1}{(j \omega C)},
\end{aligned}
$$




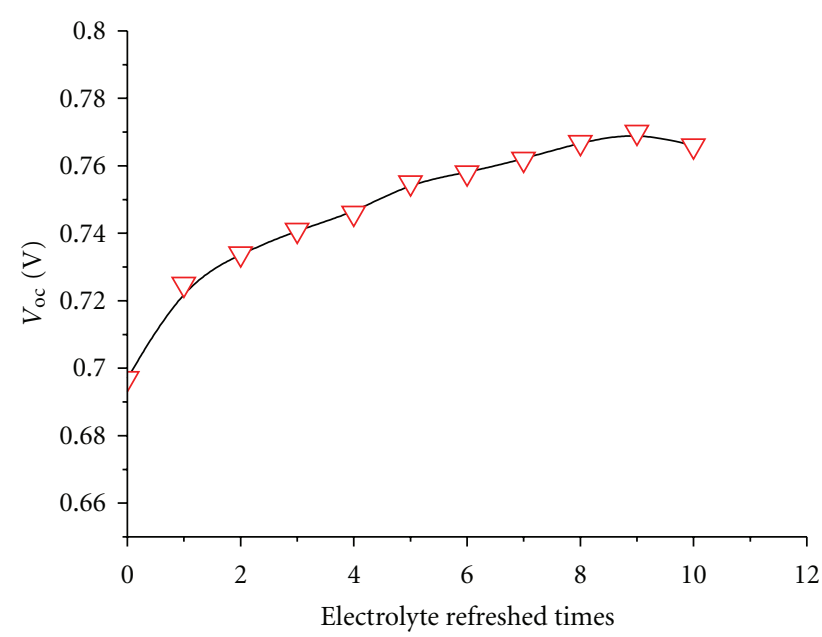

(a)

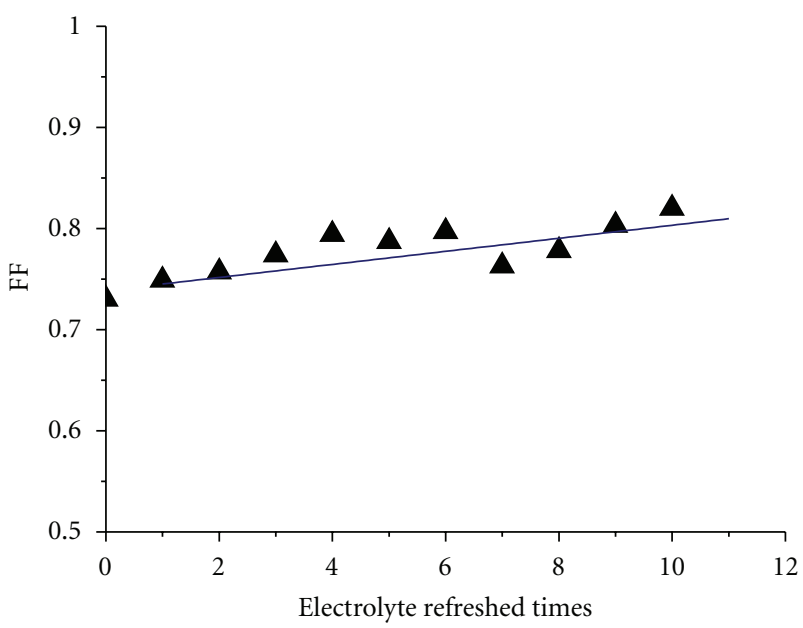

(c)

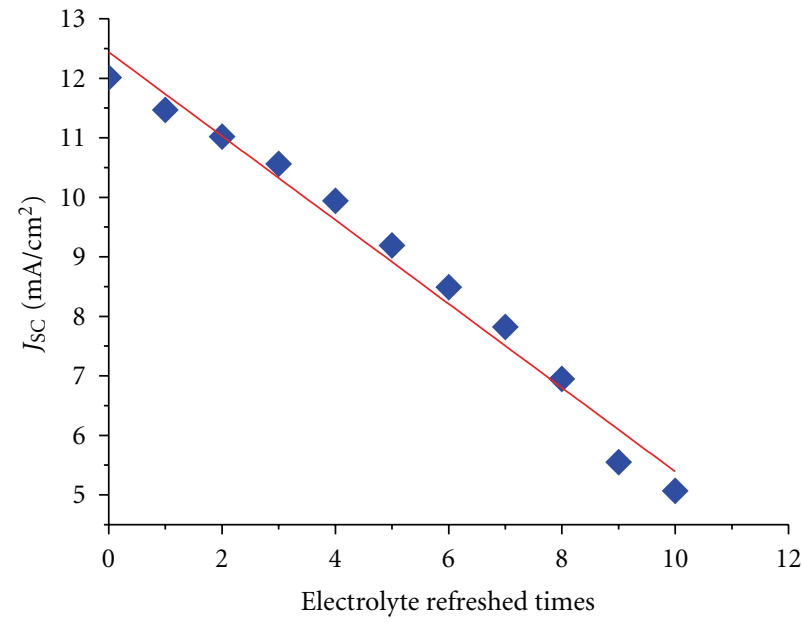

(b)

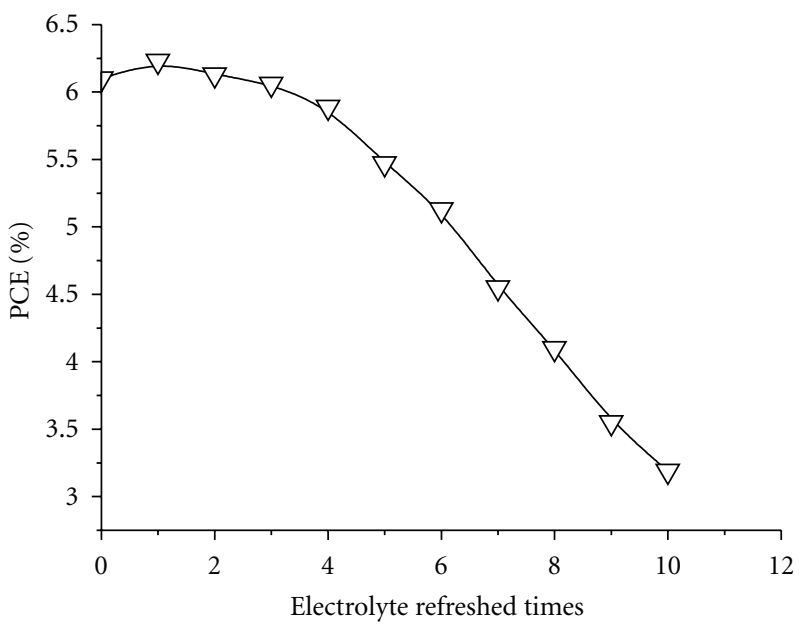

(d)

FIgURe 3: Dependency of $V_{\text {oc }}(\mathrm{a}), J_{\mathrm{sc}}(\mathrm{b}), \mathrm{FF}$ (c), and PCE (d) on electrolyte refreshing times.

where $C$ is the interface capacitance. $R_{\mathrm{ct}, \mathrm{WE}}$ and its parallel $\mathrm{CPE}$ describe the interfacial charge recombination reaction of electrons with the $\mathrm{I}_{3}^{-}$ions and chemical capacitance at $\mathrm{TiO}_{2}$ /electrolyte interface, respectively. $W$ is the impedance for the ion diffusion of electrolytes. For $R_{\mathrm{ct}, \mathrm{WE}}[32,33]$,

$$
\begin{aligned}
R_{\mathrm{CT}, \mathrm{WE}} & =\frac{1}{e}\left(\frac{\partial j_{\mathrm{rec}}}{\partial F_{n}}\right)^{-1} \\
= & R_{0} \exp \left[-\frac{\beta}{k_{B} T}\left(E_{F_{n}}-E_{\text {redox }}\right)\right] \\
= & \frac{k_{B} T \tau}{n_{\mathrm{cb}} e^{2}} \\
& \tau=\sqrt{R_{\mathrm{CT}, \mathrm{WE}} C_{\mu}}, \\
C_{\mu} & =e^{2} \frac{\partial n_{\mathrm{cb}}}{\partial E_{F_{n}}}=e^{2} \frac{\bar{n}_{\mathrm{cb}}}{k_{B} T},
\end{aligned}
$$

where $j_{\text {rec }}$ is the recombination (or loss) current, $E_{\mathrm{Fn}}$ is the position of the Fermi level of electrons, $E_{\text {redox }}$ is the potential of the redox couple, $E_{\mathrm{Fn}}-E_{\text {redox }}=e V_{\text {bias }}, V_{\text {bias }}$ is the potential at the electrode, $\beta$ is the transfer coefficient, $R_{0}$ is a constant, $k_{B}$ is the Boltzmann constant, $T$ is the absolute temperature, $n_{\mathrm{cb}}$ is the electron density of the $\mathrm{TiO}_{2}$ conduction band, $C_{\mu}$ is the $\mathrm{TiO}_{2} /$ electrolyte interface capacitance, $\tau$ is the electron life time, $e$ is the unit charge, $F_{n}$ is the Fermi level of $\mathrm{TiO}_{2}$, and $\bar{n}_{\mathrm{cb}}$ is the average electron density of the $\mathrm{TiO}_{2}$ conduction band.

By fitting the experimental data, the useful parameters for understanding the underlying mechanisms of electron transport and recombination were attained, as indicated in Figure 5. The electron combination $R_{\mathrm{ct}, \mathrm{WE}}$ (Figure 5(a)) increased from $47.8 \Omega$ at the initial to $340 \Omega$ at the tenth electrolyte refreshing. According to (4), at the very same $V_{\text {bias }}\left(E_{\mathrm{Fn}}-E_{\text {redox }}=e V_{\text {bias }}\right)$, the recombination (or loss) current $j_{\text {rec }}$ decreases with increased electrolyte refreshing time and electron time $\tau$, as shown in Figure 5(b). Consequently, (7) could be derived as follows [32, 33]:

$$
\frac{1}{e}\left(\frac{\partial j_{\mathrm{rec}}}{\partial F_{n}}\right)^{-1}=R_{0} \exp \left[-\frac{e \beta}{k_{B} T} V_{\mathrm{oc}}\right]
$$




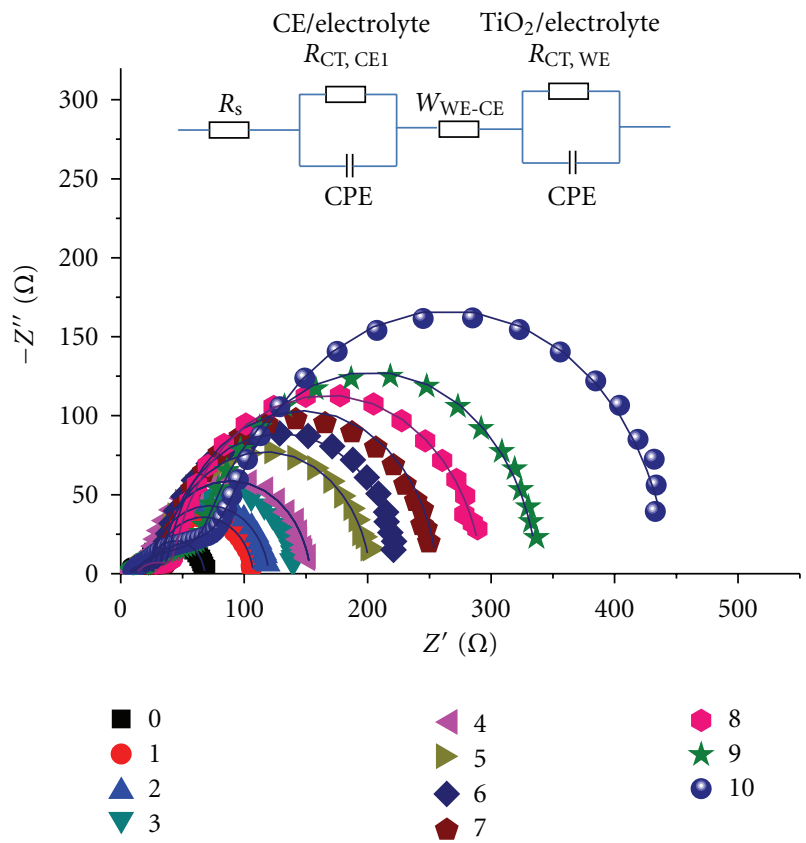

FIgURE 4: The Nyquist plots of the corresponding DSSCs under various electrolyte refreshing times in the dark at an applied forward bias of $-0.75 \mathrm{~V}$. The dot is the experiment data and the line is the fitting data via the inset equivalent circuit.

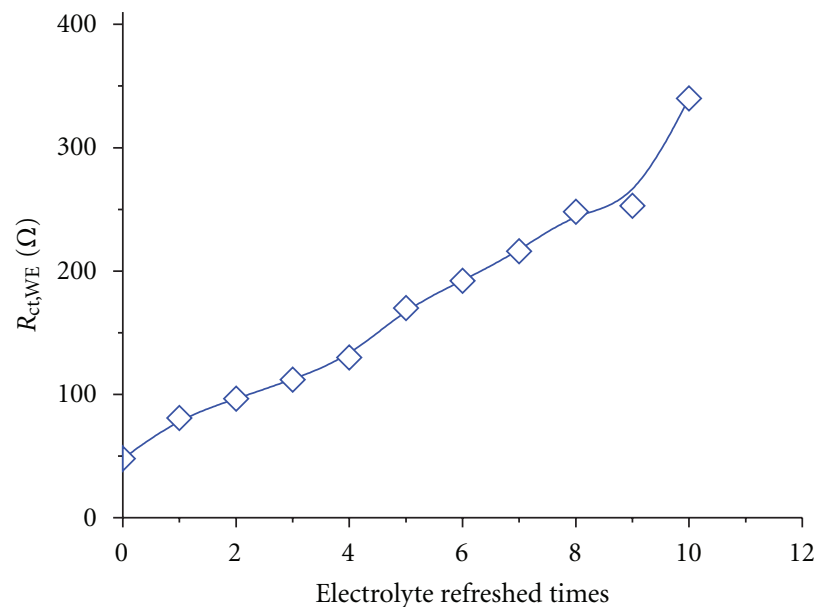

(a)

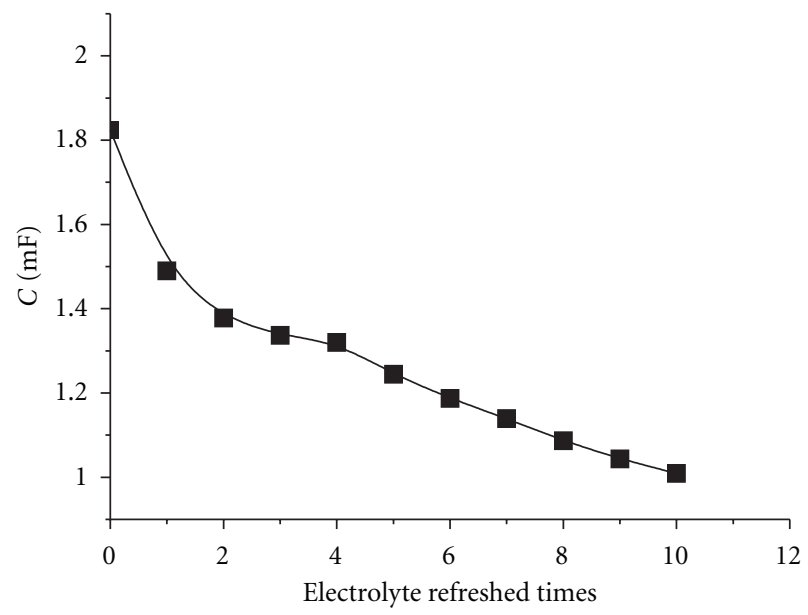

(c)

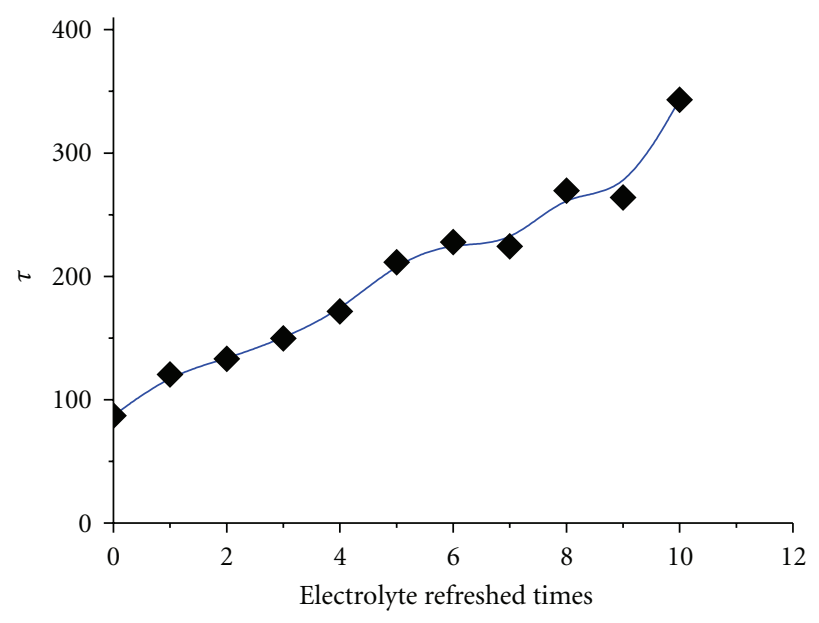

(b)

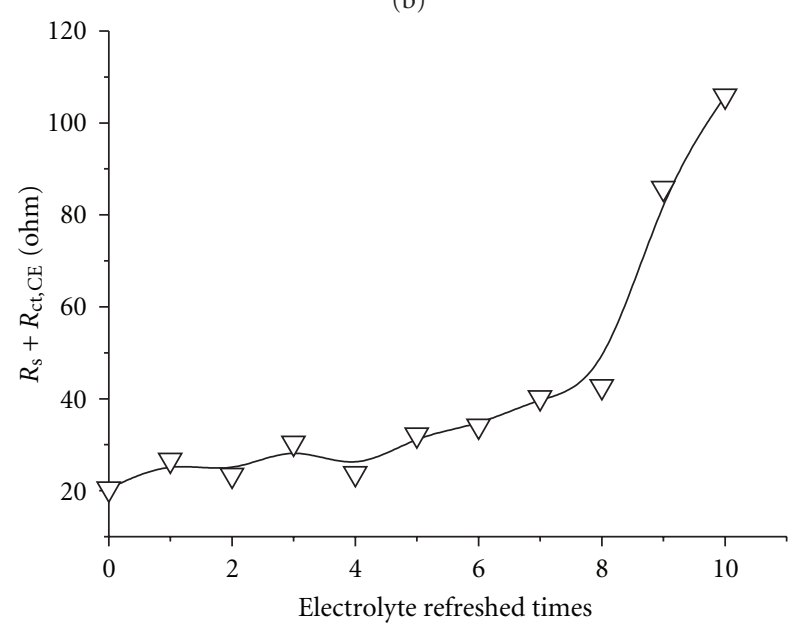

(d)

FIgURE 5: Characteristic parameters $R_{\mathrm{ct}, \mathrm{WE}}(\mathrm{a})$, electron life time $\tau$ (b), chemical capacity $C$ (c), and $R_{\mathrm{s}}+R_{\mathrm{ct}, \mathrm{CE}}(\mathrm{d})$ of the arc impedance spectra of DSSCs with various electrolyte refreshing times in the dark at an applied forward bias of $-0.75 \mathrm{~V}$. 


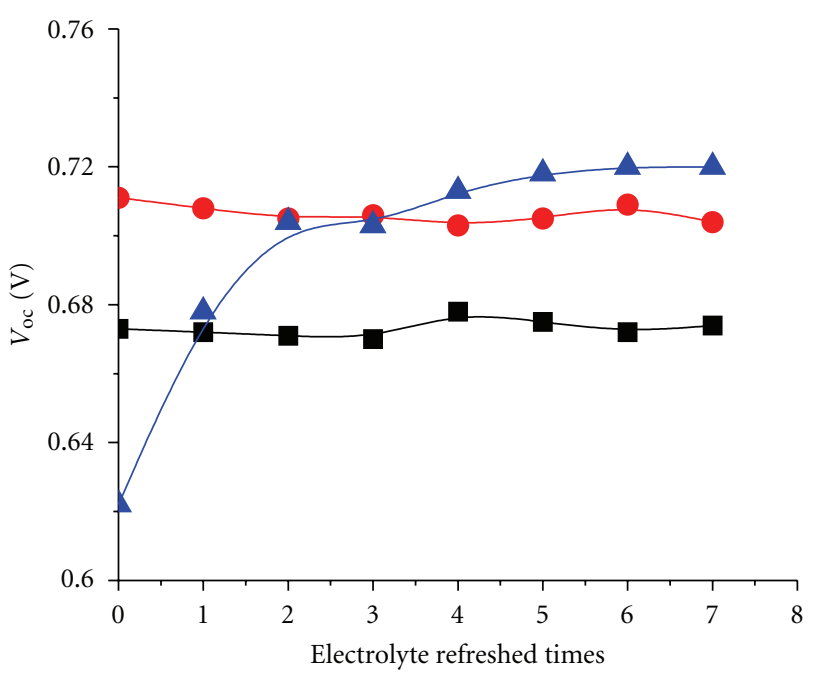

(a)

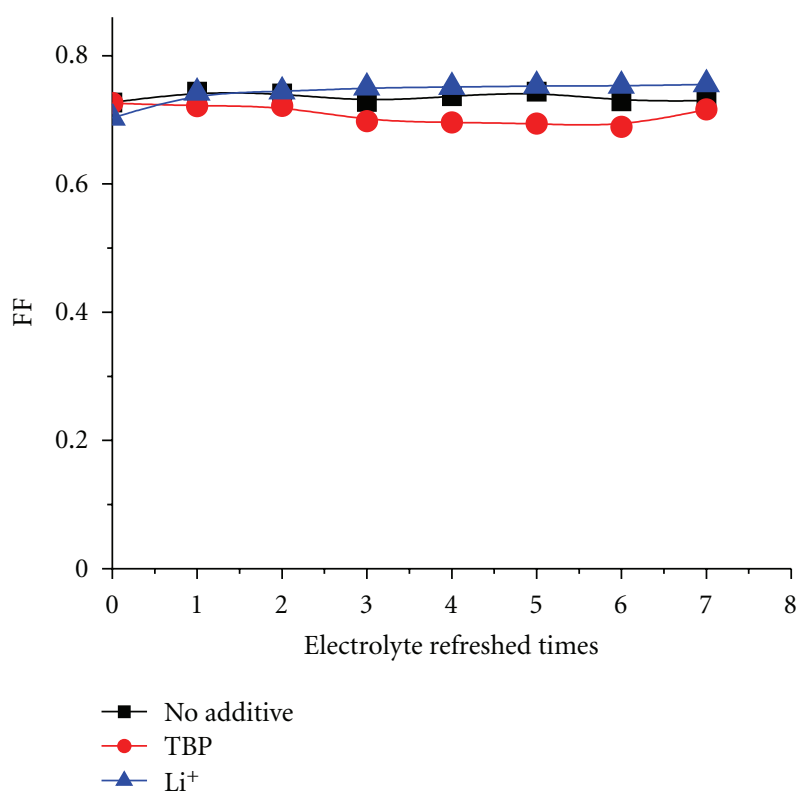

(c)

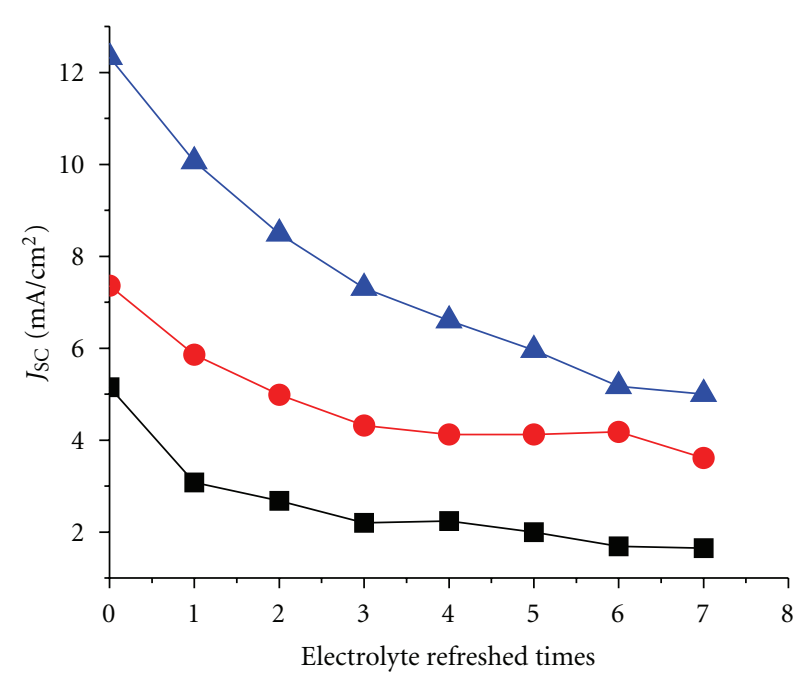

(b)

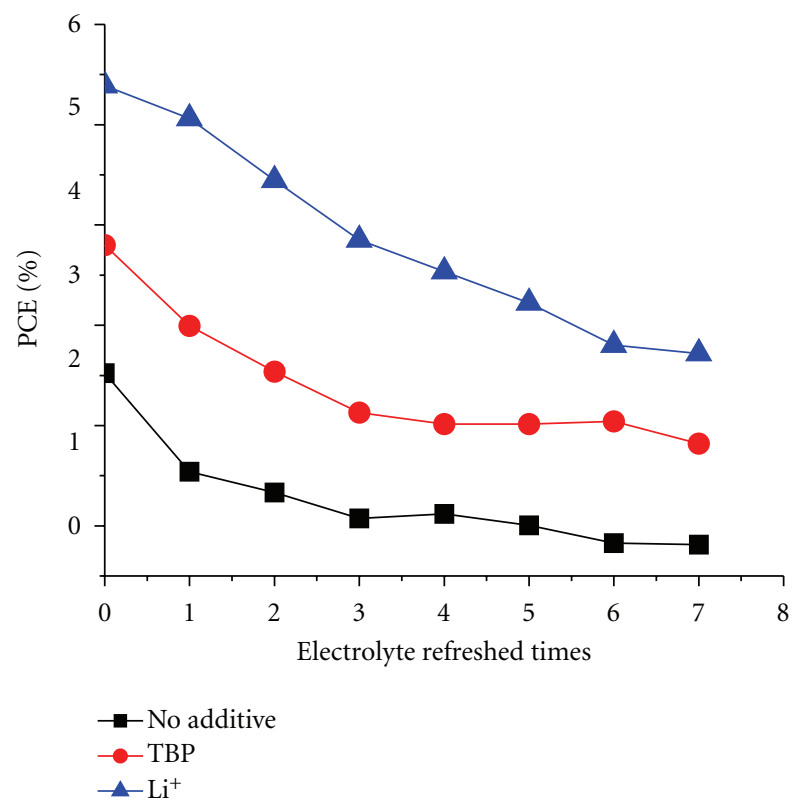

(d)

FIGURE 6: $I-V$ parameters $\left(V_{\mathrm{oc}}(\mathrm{a}), J_{\mathrm{sc}}(\mathrm{b}), \mathrm{FF}(\mathrm{c})\right.$, and PCE $\left.(\mathrm{d})\right)$ of devices based on different electrolytes varied with electrolyte refreshing times. No additive: $0.04 \mathrm{M} \mathrm{I}_{2}$ and $0.6 \mathrm{M} \mathrm{BMII}$; TBP: $0.04 \mathrm{M} \mathrm{I}_{2}, 0.6 \mathrm{M}$ BMII, and 0.03 M TBP; $\mathrm{Li}^{+}$: 0.04 M I, $0.6 \mathrm{M} \mathrm{BMII,} \mathrm{and} \mathrm{0.05} \mathrm{M} \mathrm{LiI.}$

Therefore, under the same illumination, there would be less electron recombination and larger $V_{\mathrm{oc}}$. This conclusion was consistent with the dark current shown in Figure 1(b) and with the conclusions derived from (1) and (2).

As aforementioned, $J_{\mathrm{sc}}$ declined with electrolyte refreshing. This finding may be ascribed to several aspects. On one hand, it was due to dye desorption. Figure 5(c) shows that the $\mathrm{TiO}_{2} /$ electrolyte interface capacitance $C_{\mu}$ decreased with electrolyte refreshing. According to (6), $\bar{n}_{\mathrm{cb}}$ decreases with electrolyte refreshing. This tendency indicates less photocurrent injected into the $\mathrm{TiO}_{2}$ from the excited dye, which may be due to dye desorption. On the other hand, the increased $R_{\mathrm{S}}+R_{\mathrm{ct}, \mathrm{CE}}$ with electrolyte refreshing (Figure 5(d)) decreased the $J_{\mathrm{sc}}$ [31], which was likely to the electrolyte corrosion of the counter electrolyte [34].
The additive TBP and $\mathrm{Li}^{+}$play important roles in maintaining a high $V_{\mathrm{oc}}[35,36]$. The tendency shown in Figure 3 may be attributed to the remaining additive in the solar cell with electrolyte refreshing. To prove this assumption, the electrolyte refreshing effects on devices based on different electrolytes $\mathrm{A}, \mathrm{B}$, and $\mathrm{C}$ were investigated. The contents of electrolytes A, B, and C were detailed as follows: A: $0.04 \mathrm{M} \mathrm{I}_{2}$ and 0.6 M BMII; B: 0.04 $\mathrm{M} \mathrm{I}_{2}, 0.6 \mathrm{M}$ BMII, and $0.03 \mathrm{M}$ TBP; C: $0.04 \mathrm{M} \mathrm{I}_{2}, 0.6 \mathrm{M} \mathrm{BMII}$, and $0.05 \mathrm{M}$ LiI. All the $I-V$ parameters of the devices based on $\mathrm{A}, \mathrm{B}$, and $\mathrm{C}$ are shown in Figure 6. In Figure 5(a), $V_{\text {oc }}$ of the devices based on A and B changed little, whereas that of the devices based on $\mathrm{C}$ obviously increased with electrolyte refreshing. FF of all the devices only slightly changed with electrolyte refreshing. $J_{\mathrm{sc}}$ and PCE of all the devices decline in a similar tendency, 
which can be ascribed to the interface charge transport and recombination analyzed in the previous parts. Therefore, we could conclude from Figure 6 that the remaining $\mathrm{Li}^{+}$significantly influenced $V_{\text {oc }}$ with electrolyte refreshing, the remaining TBP little influenced $V_{\text {oc }}$ with electrolyte refreshing and the factors that decreased $J_{\mathrm{sc}}$ were mainly related to the decreased PCE. Comparing Figures 3 and 6, we could find that $V_{\mathrm{oc}}$ of devices based on electrolyte with both TBP and $\mathrm{Li}^{+}$was larger than that of $\mathrm{A}, \mathrm{B}, \mathrm{C}$, which were based on electrolyte with no additive, with TBP only and with $\mathrm{Li}^{+}$only, respectively. It is confirmed that TBP and $\mathrm{Li}^{+}$were in synergism to increase $V_{\mathrm{oc}}$.

\section{Conclusions}

The effect of electrolyte refreshing on the photovoltaic performance of FDSSCs was studied. The electron transport and interfacial recombination kinetics were also systematically investigated by EIS. With increased electrolyte refreshing times from 0 to 10 times, FF and especially $V_{\text {oc }}$ increased, whereas $J_{\mathrm{sc}}$ and PCE significantly decreased. The increase in $V_{\text {oc }}$ was mainly ascribed to less electron recombination with the $\mathrm{I}_{3}^{-}$ions as the electrolytes were refreshed according to EIS. $\mathrm{Li}^{+}$also played a critical role in $V_{\mathrm{oc}}$, increase and it worked with TBP synergistically to improve $V_{\text {oc }}$. The decline in $J_{\text {sc }}$ and PCE was primarily brought about by dye desorption and the increase of series resistance.

\section{Acknowledgments}

This work was jointly supported by the NSFC (50833001), MOST (2011CB933300), and MOE (309001) of China.

\section{References}

[1] B. O’Regan and M. Grätzel, "A low-cost, high-efficiency solar cell based on dye-sensitized colloidal $\mathrm{TiO}_{2}$ films," Nature, vol. 353, no. 6346, pp. 737-740, 1991.

[2] M. Grätzel, "Photoelectrochemical cells," Nature, vol. 414, no. 6861, pp. 338-344, 2001.

[3] M. K. Nazeeruddin, A. Kay, I. Rodicio et al., "Conversion of light to electricity by cis-X2bis (2, 2'-bipyridyl-4, 4' -dicarboxylate)ruthenium(II) charge-transfer sensitizers ( $\mathrm{X}=\mathrm{Cl}$-, $\mathrm{Br}-$, I-, CN-, and SCN-) on nanocrystalline $\mathrm{TiO}_{2}$ electrodes," Journal of the American Chemical Society, vol. 115, no. 14, pp. 6382-6390, 1993.

[4] J. E. Moser, P. Bonnôte, and M. Grätzel, "Molecular photovoltaics," Coordination Chemistry Reviews, vol. 171, no. 1, pp. 245-250, 1998.

[5] L. M. Goncalves, V. De Zea Bermudez, H. A. Ribeiro, and A. M. Mendes, "Dye-sensitized solar cells: a safe bet for the future," Energy and Environmental Science, vol. 1, no. 6, pp. 655-667, 2008.

[6] Q. Yu, Y. Wang, Z. Yi et al., "High-efficiency dye-sensitized solar cells: the influence of lithium ions on exciton dissociation, charge recombination, and surface states," ACS Nano, vol. 4, no. 10, pp. 6032-6038, 2010.

[7] L. Han, A. Fukui, Y. Chiba et al., "Integrated dye-sensitized solar cell module with conversion efficiency of 8.2\%," Applied Physics Letters, vol. 94, no. 1, Article ID 013305, 2009.
[8] X. Fan, Z. Chu, F. Wang, L. Chen, Y. Tang, and D. Zou, "Wireshaped flexible dye-sensitized solar cells," Advanced Materials, vol. 20, no. 3, pp. 592-595, 2008.

[9] M. R. Lee, R. D. Eckert, K. Forberich, G. Dennler, C. J. Brabec, and R. A. Gaudiana, "Solar power wires based on organic photovoltaic materials," Science, vol. 324, no. 5924, pp. 232-235, 2009.

[10] H. Wang, Y. Liu, M. Li, H. Huang, M. Zhong, and H. Shen, "Hydrothermal growth of large-scale macroporous $\mathrm{TiO}_{2}$ nanowires and its application in 3D dye-sensitized solar cells," Applied Physics A, vol. 97, no. 1, pp. 25-29, 2009.

[11] B. Weintraub, Y. G. Wei, and Z. L. Wang, "Optical fiber/nanowire hybrid structures for efficient three-dimensional dyesensitized solar cells," Angewandte Chemie, vol. 48, no. 47, pp. 8981-8985, 2009.

[12] S. Huang, Q. Zhang, X. Huang et al., "Fibrous CdS/CdSe quantum dot co-sensitized solar cells based on ordered $\mathrm{TiO}_{2}$ nanotube arrays ," Nanotechnology, vol. 21, no. 37, Article ID 375201, 2010.

[13] Y. Liu, M. Li, H. Wang et al., "Synthesis of $\mathrm{TiO}_{2}$ nanotube arrays and its application in mini-3D dye-sensitized solar cells," Journal of Physics D, vol. 43, no. 20, 2010.

[14] B. O'Connor, D. Nothern, K. P. Pipe, and M. Shtein, "High efficiency, broadband solar cell architectures based on arrays of volumetrically distributed narrowband photovoltaic fibers," Optics Express, vol. 18, no. 19, pp. A432-A443, 2010.

[15] D. Zou, D. Wang, Z. Chu, Z. Lv, and X. Fan, "Fiber-shaped flexible solar cells," Coordination Chemistry Reviews, vol. 254, no. 9-10, pp. 1169-1178, 2010.

[16] J. Bae, Y. J. Park, M. Lee et al., "Single-fiber-based hybridization of energy converters and storage units using graphene as electrodes," Advanced Materials, vol. 23, no. 30, pp. 34463449, 2011.

[17] T. Chen, S. Wang, Z. Yang et al., "Flexible, light-weight, ultrastrong, and semiconductive carbon nanotube fibers for a highly efficient solar cell," Angewandte Chemie, vol. 50, no. 8, pp. 1815-1819, 2011.

[18] Y. Fu, Z. Lv, S. Hou et al., "Conjunction of fiber solar cells with groovy micro-reflectors as highly efficient energy harvesters," Energy and Environmental Science, vol. 4, no. 9, pp. 3379-3383, 2011.

[19] S. Huang, X. Guo, X. Huang et al., "Highly efficient fibrous dye-sensitized solar cells based on $\mathrm{TiO}_{2}$ nanotube arrays," Nanotechnology, vol. 22, no. 31, Article ID 315402, 2011.

[20] Z. Lv, Y. Fu, S. Hou et al., "Large size, high efficiency fibershaped dye-sensitized solar cells," Physical Chemistry Chemical Physics, vol. 13, no. 21, pp. 10076-10083, 2011.

[21] D. Wang, S. Hou, H. Wu, C. Zhang, Z. Chu, and D. Zou, "Fiber-shaped all-solid state dye sensitized solar cell with remarkably enhanced performance via substrate surface engineering and $\mathrm{TiO}_{2}$ film modification," Journal of Materials Chemistry, vol. 21, no. 17, pp. 6383-6388, 2011.

[22] J. Yu, D. Wang, Y. Huang et al., "A cylindrical core-shelllike $\mathrm{TiO}_{2}$ nanotube array anode for flexible fiber-type dyesensitized solar cells," Nanoscale Research Letters, vol. 6, article 94, 2011.

[23] K. Okada, H. Matsui, T. Kawashima, T. Ezure, and N. Tanabe, "100 mm $\times 100 \mathrm{~mm}$ large-sized dye sensitized solar cells," Journal of Photochemistry and Photobiology A, vol. 164, no. 13, pp. 193-198, 2004.

[24] M. A. Green, "Consolidation of thin-film photovoltaic technology: the coming decade of opportunity," Progress in Photovoltaics, vol. 14, no. 5, pp. 383-392, 2006. 
[25] M. L. Rosenbluth and N. S. Lewis, "'Ideal' behavior of the open circuit voltage of semiconductor/liquid junctions," The Journal of Physical Chemistry, vol. 93, no. 9, pp. 3735-3740, 1989.

[26] A. Kumar, P. G. Santangelo, and N. S. Lewis, "Electrolysis of water at SrTiO3 photoelectrodes: distinguishing between the statistical and stochastic formalisms for electron-transfer processes in fuel-forming photoelectrochemical systems," The Journal of Physical Chemistry, vol. 96, no. 2, pp. 834-842, 1992.

[27] J. Bisquert, "Theory of the impedance of electron diffusion and recombination in a thin layer," The Journal of Physical Chemistry B, vol. 106, no. 2, pp. 325-333, 2002.

[28] J. Bisquert, A. Zaban, and P. Salvador, "Analysis of the mechanisms of electron recombination in nanoporous $\mathrm{TiO}_{2}$ dyesensitized solar cells. Nonequilibrium steady-state statistics and interfacial electron transfer via surface states," The Journal of Physical Chemistry B, vol. 106, no. 34, pp. 8774-8782, 2002.

[29] I. Morá-Seró and J. Bisquert, "Effect of reduced selectivity of contacts on the current-potential characteristics and conversion performance of solar cells," Solar Energy Materials and Solar Cells, vol. 85, no. 1, pp. 51-62, 2005.

[30] Q. Wang, J. E. Moser, and M. Grätzel, "Electrochemical impedance spectroscopic analysis of dye-sensitized solar cells," The Journal of Physical Chemistry B, vol. 109, no. 31, pp. 1494514953, 2005.

[31] Q. Wang, S. Ito, M. Grätzel et al., "Characteristics of high efficiency dye-sensitized solar cells," The Journal of Physical Chemistry B, vol. 110, no. 50, pp. 25210-25221, 2006.

[32] F. Fabregat-Santiago, J. Bisquert, E. Palomares et al., "Correlation between photovoltaic performance and impedance spectroscopy of dye-sensitized solar cells based on ionic liquids," The Journal of Physical Chemistry C, vol. 111, no. 17, pp. 6550-6560, 2007.

[33] I. Mora-Seró, J. Bisquert, F. Fabregat-Santiago et al., "Implications of the negative capacitance observed at forward bias in nanocomposite and polycrystalline solar cells," Nano Letters, vol. 6, no. 4, pp. 640-650, 2006.

[34] T. N. Murakami, S. Ito, Q. Wang et al., "Highly efficient dyesensitized solar cells based on carbon black counter electrodes," Journal of the Electrochemical Society, vol. 153, no. 12, Article ID 047612JES, pp. A2255-A2261, 2006.

[35] S. Rühle, M. Greenshtein, S. G. Chen et al., "Molecular adjustment of the electronic properties of nanoporous electrodes in dye-sensitized solar cells," The Journal of Physical Chemistry B, vol. 109, no. 40, pp. 18907-18913, 2005.

[36] K. Ryuzi, K. Motohiro, S. Kodate, A. Furube, N. Fuke, and N. Koide, "Effects of 4-tert-butylpyridine and li ions on photoinduced electron injection efficiency in black-dye-sensitized Nanocrystalline $\mathrm{TiO}_{2}$ films," The Journal of Physical Chemistry C, vol. 113, no. 48, pp. 20738-20744, 2009. 


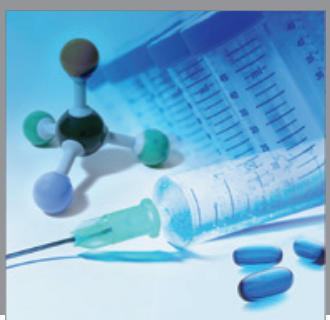

International Journal of

Medicinal Chemistry

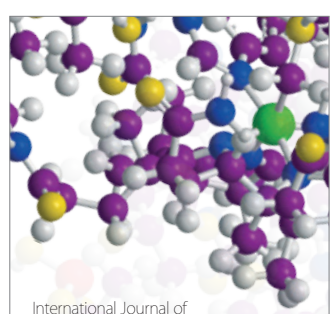

Carbohydrate Chemistry

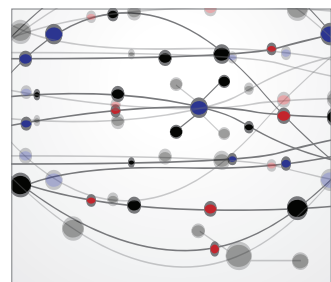

The Scientific World Journal
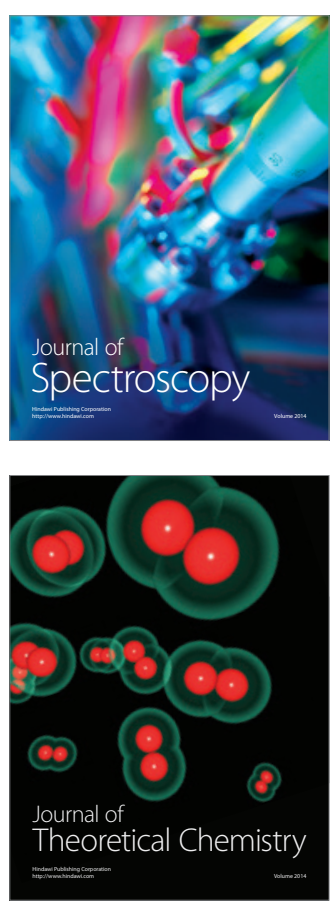
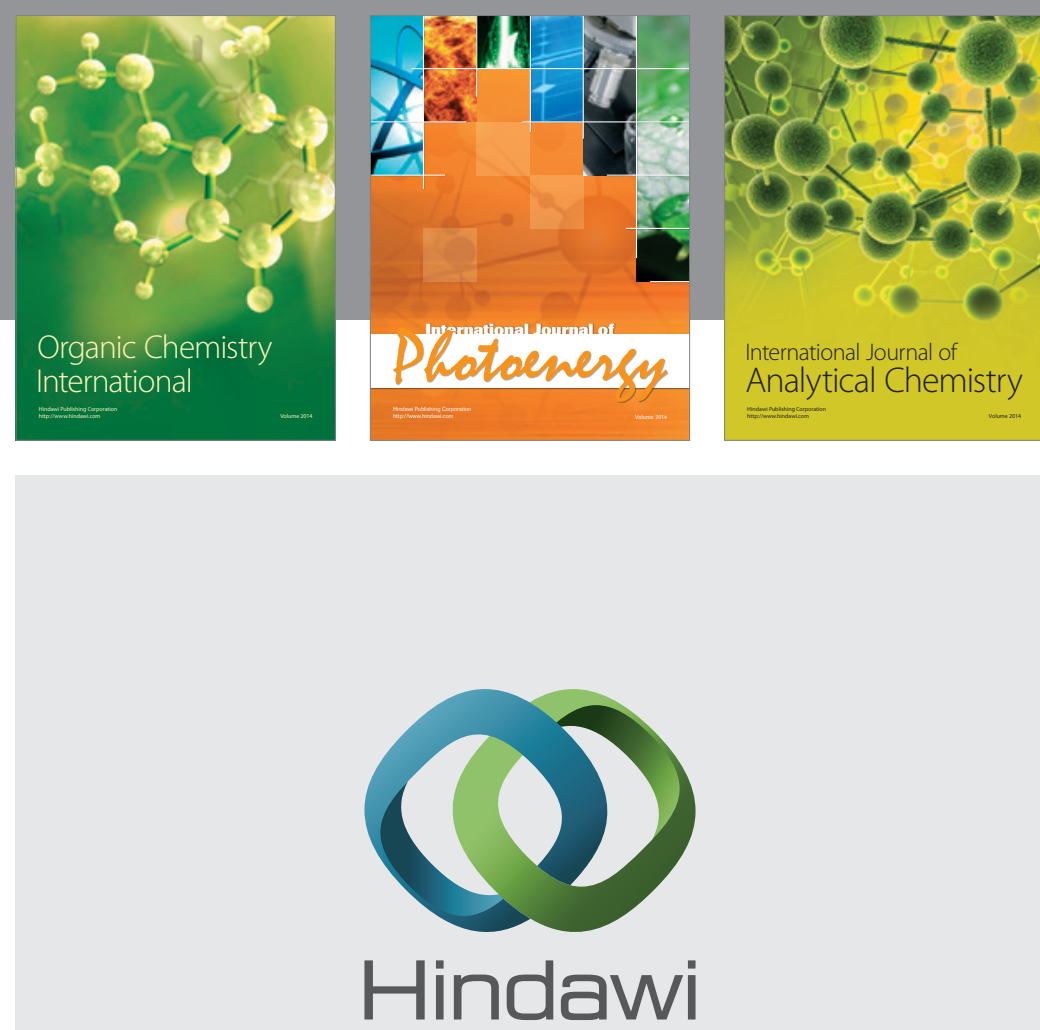

Submit your manuscripts at

http://www.hindawi.com
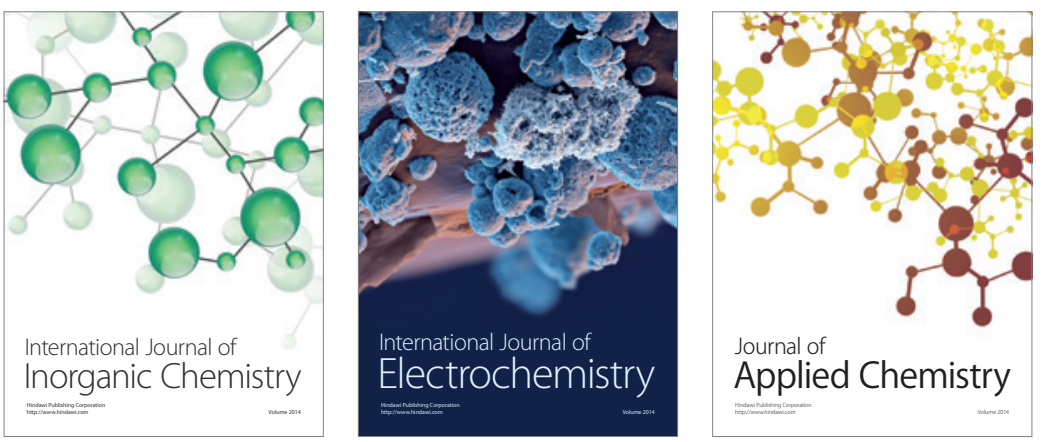

Journal of

Applied Chemistry
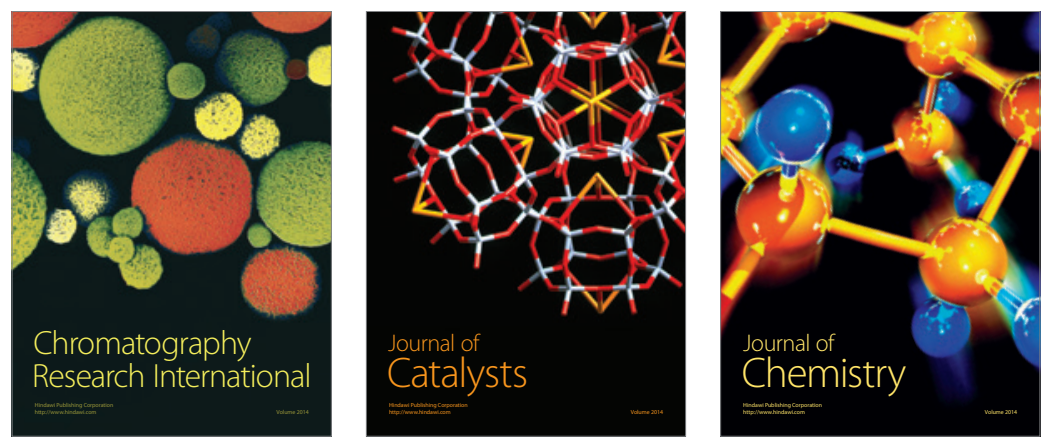
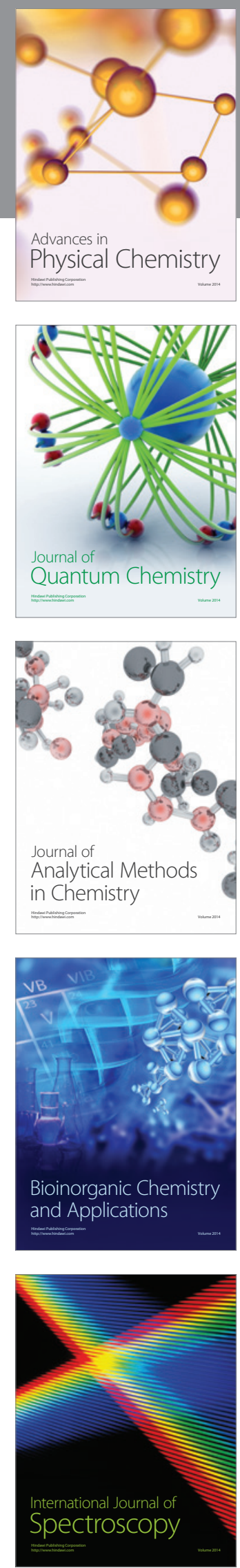